\title{
Day-To-Day Home Blood Pressure Variability and All-Cause Mortality in a Memory Clinic Population
}

\author{
Rinske A. Haverkamp ${ }^{\mathrm{a}}$, René J.F. Melis ${ }^{\mathrm{b}}$, Jurgen A.H.R. Claassen ${ }^{\mathrm{a}, *}$ and Rianne A.A. de Heus ${ }^{\mathrm{a}}$ \\ ${ }^{a}$ Radboud University Medical Center, Donders Institute for Brain Cognition and Behaviour, Department of \\ Geriatric Medicine, Radboudumc Alzheimer Center, Nijmegen, The Netherlands \\ ${ }^{\mathrm{b}}$ Radboud University Medical Center, Radboud Institute for Health Sciences, Department of Geriatric Medicine, \\ Radboudumc Alzheimer Center, Nijmegen, The Netherlands
}

Handling Associate Editor: Rónán O’Caoimh

Accepted 5 November 2021

Pre-press 15 December 2021

\begin{abstract}
.
Background: High day-to-day blood pressure variability (BPV) has been associated with an increased risk for cognitive decline and mortality in the general population. Whether BPV is associated with increased all-cause mortality in older people with cognitive impairment is unknown.

Objective: To investigate the association between day-to-day home BPV and all-cause mortality in older patients attending a memory clinic.

Methods: We included 279 patients attending a memory clinic, who measured home blood pressure (BP) for 7 consecutive days in the morning and evening. Within-subject BPV was defined as the variation independent of the mean (VIM). Timeto-death was verified through the Dutch population registry. Cox proportional hazard regression was used. Separate analyses were performed for morning-to-morning and evening-to-evening BPV.

Results: Mean age was $73 \pm 9$ years, dementia and mild cognitive impairment were diagnosed in $35 \%$ and $34 \%$ respectively, and mean home BP was $139 / 79 \mathrm{mmHg}$. After a mean follow-up of 3.2 years, 52 patients had died. Neither day-to-day systolic nor diastolic VIM were associated with mortality (adjusted hazard ratio [HR] systolic VIM: 0.99, 95\%-CI 0.92-1.06, $p=0.770$, HR diastolic VIM: 1.04, 95\%-CI 0.93-1.17, $p=0.517$ ). When morning and evening measurements were analyzed separately, systolic morning-to-morning VIM was associated with mortality (adjusted HR: 1.09, 95\%-CI 1.01-1.18, $p=0.033$ ).

Conclusion: In this study, day-to-day BPV was not associated with all-cause mortality in patients attending a memory clinic. However, morning-to-morning BPV was. Due to the short assessment window, there is still a lack of clarity; hence future research is warranted to clarify the role of all BPV components in aging.
\end{abstract}

Keywords: Alzheimer, cardiovascular risk management, dementia, geriatrics, home blood pressure monitoring, hypertension

\footnotetext{
*Correspondence to: Jurgen Claassen, MD, PhD, Department of Geriatric Medicine, Radboud University Medical Center, P.O. Box 9101 (925), 6500 HB Nijmegen, the Netherlands. Tel.: +31 24 3619332; E-mail: Jurgen.Claassen@ radboudumc.nl.
}

\section{INTRODUCTION}

Hypertension has a high worldwide burden of disease, is one of the strongest risk factors for cardiovascular diseases (CVD), and leads to a higher risk for mortality [1-3]. Studies have convincingly reported that chronic hypertension during mid-life is also a strong risk factor for cognitive impairment in 
late-life [4-6]. However, the role of late-life blood pressure (BP) in the risk for cognitive decline and dementia remains inconclusive [7-9], and optimal BP targets in those with cognitive impairment are unknown, leading to the lack of clear clinical guidelines for BP management in older frail people [10]. Furthermore, little is known about factors that are associated with the heterogeneous prognosis of cognitive impairment [11]. More knowledge of factors that can forecast the longitudinal course of an individual with dementia is of importance for society and patients, and is relevant for BP management, since with a poor life expectancy the benefit-risk ratio of treatment changes.

Historically, BP management and research have focused on the effects of mean BP. However, BP is known to have noticeable fluctuations over time, such as minutes, hours, days, and months. Over the past two decades, this so-called blood pressure variability (BPV) has attracted attention and is no longer considered a random phenomenon [12]. High BPV has been related to CVD, stroke, and cerebral small vessel disease [13-15]. Moreover, studies have found an association between high BPV and all-cause mortality in the general population [16-19]. These studies measured BPV over a period of months or years, called visit-to-visit BPV. This long exposure time hampers the use of this information in clinical practice. BPV measured at home over a period of several consecutive days, day-to-day BPV, is likely to have a better clinical applicability. It provides information on the consistency of BP within a shorter timeframe, is more reproducible, offers better prognostic value [20] and out-of-office measurements are generally more representative for actual BP than office measurements [10, 21]. Day-to-day BPV has also been related to all-cause mortality in the general population, albeit with less evidence [22-24].

Previous work has linked both high visit-to-visit and day-to-day BPV to an increased risk for cognitive decline and dementia [25]. Moreover, in patients with pre-existent Alzheimer's disease (AD), high BPV was associated with increased progression of $\mathrm{AD}$ $[26,27]$, although this was not found in all single studies [28]. It is hypothesized that the alterations in cerebral hemodynamic and damage on cerebral microvasculature caused by high BPV, may promote AD pathophysiology [27, 29]. However, causality remains unclear and a bidirectional relationship is suggested, since there is also growing evidence that $\mathrm{BPV}$ is increased among AD patients compared to cognitive normal controls [29].
In addition, high BPV was associated with higher odds for vascular damage such as cerebral small vessel disease, which in turn contributes to a heightened risk for mortality [30, 31]. Older people with dementia often present with a mix of $\mathrm{AD}$ and vascular pathology [32], both being associated with increased BPV. Whether high day-to-day BPV is associated with mortality in this group is unknown. Exploring this association could provide new insights in the ongoing debate regarding what to focus on in the BP management in this vulnerable group, if we understand how day-to-day BPV variability is related to the prognosis of patients with dementia.

The population attending a memory clinic comprises people with newly diagnosed dementia, mild cognitive impairment or at risk for dementia. As such, they represent the population in which uncertainties exist regarding optimal BP management, the associations of BPV with dementia and/or mortality, and regarding individual prognosis. Therefore, we studied a population of older people attending a university hospital memory clinic and aimed to investigate the association between day-to-day BPV and all-cause mortality. We studied day-to-day BPV because of the shorter timeframe in which this can be collected and the higher potential for clinical practice, compared to visit-to-visit BPV. Secondary aims were subgroup analysis of participants with dementia, morning-to-morning versus evening-to-evening $\mathrm{BPV}$, and to investigate the effects of different lengths of follow-up, since this might result in different insights [33].

\section{METHODS}

\section{Study design and participants}

In this observational retrospective cohort study, a database consisting of older people attending the memory clinic of the Radboud university medical center (Nijmegen, The Netherlands) was used. This database and protocol have also been described elsewhere, and this is a secondary analysis of an existing database [34, 35]. Inclusion started in January 2014 and lasted until July 2019. All eligible patients who visited the memory clinic were asked to perform home blood pressure measurement (HBPM); there was no age or cognitive test score cut-off. Eligibility was judged by the attending physician or nurse and based on the capability to understand the Dutch language and to perform the BP measurements at home. If necessary, patients could be aided by a proxy who 
also received instructions, to improve eligibility of the measurements. The study was reviewed and approved by the Medical Ethics Committee (CMO ArnhemNijmegen, file number 2016-2753), who exempted the study from the need to obtain written informed consent, because of the minimal burden of the measurements. Oral informed consent was asked from each patient and, if applicable, their informal caregiver.

In total, 340 patients agreed to participate in the study. Of these, 10 participants performed 0 BP measurements, of 8 participants the medical records were missing in the database, 5 participants in the database were seen at the 'diagnostic day center' instead of the memory clinic, 1 participant did not provide consent for the use of information extracted from medical records, and 1 participant died from brain metastases soon after measurements were taken. These participants were excluded from further analysis, leaving 315 participants in the current study.

\section{Home blood pressure measurements}

Participants received instructions, both written and oral, on how to perform HBPM. If possible, or necessary, they could be aided by their caregiver. An automatic oscillometric device with a memory function was used (Microlife WatchBP Home, Microlife, Heerbrugg, Switzerland) [36], and the measurements were carried out according to an international protocol [21]. This protocol consisted of the instruction to measure BP twice a day: in the morning (4.00-11.00 am) and in the evening (4.00-11.00 pm), for 7 consecutive days. Participants received instruction to rest for $5 \mathrm{~min}$ before measuring $\mathrm{BP}$ and not to measure within $1 \mathrm{~h}$ after food or drug intake. During each measurement, two BP readings were performed. These duplicate readings were averaged, and measurements of the first day were removed, as by standard practice. A minimum of 8 (out of 12) duplicate measurements was set as a requirement to be included in the analysis. Morning and evening BP measurements were also analyzed separately and are further on referred to as "morning-to-morning" and "evening-to-evening" BPV. For these analyses, a minimum of 4 duplicate measurements was required.

BPV was evaluated using two parameters: The variation independent of the mean (VIM) and coefficient of variation $(\mathrm{CV})$. The $\mathrm{CV}$ is calculated by dividing the standard deviation (SD) with the mean $\left(\mathrm{CV}=\mathrm{SD} / \mathrm{mean}^{*} 100 \%\right)$, but can still be correlated to mean BP [13]. Therefore, VIM has been developed as a new measure uncorrelated with mean BP [13]. VIM was determined by the formula: VIM $=\mathrm{SD} / \mathrm{mean}^{\mathrm{x}}$. The parameter $\mathrm{x}$ was estimated from fitting a curve through a plot of SD of BP ( $y$ axis) against mean BP ( $x$ axis) [13, 37]. VIM was used as the primary parameter in this study since its correlation with mean BP is almost zero. However, results are also presented for $\mathrm{CV}$, because values of VIM cannot be compared across populations. VIM and CV were determined for systolic and diastolic day-to-day, morning-to-morning and evening-to-evening BPV.

\section{Outcome}

The primary outcome in this study was all-cause mortality. No distinction could be made between different causes of death. Data on mortality was retrieved from the Dutch Personal Records Database [38] and was assessed until December 3th 2019, and this date was used as a censoring date for survivors.

\section{Other variables}

Additional information was extracted from the participant's medical record at baseline. Information included: age, gender, education level, smoking status, alcohol, body mass index (BMI), diabetes mellitus, history of CVD, hypertension, cognitive diagnosis, and current medication use. Education level was defined as low, medium, or high following the Dutch 'Verhage' system, as previously described [39]. CVD included (chronic) heart failure, coronary heart disease, cardiac arrythmias, peripheral artery disease, and cerebrovascular disease. A vascular score was calculated by scoring the presence of each of the 5 cardiovascular comorbidities + diabetes mellitus + smoking status $[8,40]$. If cardiovascular comorbidity was absent but the patient was using a statin or anticoagulants, 1 point was added to the total score, leading to a maximum score of 7. Hypertension was defined as mean home SBP $\geq 135 \mathrm{mmHg}$ and/or home DBP $\geq 85 \mathrm{mmHg}$. Cognitive diagnoses were established in a multidisciplinary meeting with geriatricians and neuropsychologists and were based on information from the geriatric assessment and international DSM-5 criteria [41], the NINCDS-ADRDA criteria for Alzheimer's disease, NINDS-AIREN criteria for vascular dementia and the criteria of Albert et al. for mild cognitive impairment (MCI) [42]. When deemed necessary, additional diagnostic testing (i.e., neuropsychological testing or neuroimaging) were performed. Patients 
were categorized into four groups: dementia (any type), MCI, subjective cognitive impairment (cognitively normal), and other diagnosis (neurological or psychiatric diagnosis such as depression).

\section{Statistical analyses}

Baseline characteristics of participants are presented as mean \pm SD for continuous variables and frequency (percentage) for categorical variables. Missing data for covariates (smoking status, vascular score) were imputed using multiple imputation with 5 chained datasets, assuming these covariates were missing at random. Extreme outliers in BPV (defined as $\geq 4 \mathrm{SD}$ from the mean) were converted to a value similar to mean +3 SDs, to limit the influence of these outliers. This was the case for 12 values of VIM ( 3 for day-to-day, 4 for morning-to-morning, 5 for evening-to-evening). The same procedure was followed for CV. Furthermore, multiple linear regression was used to assess the association between covariates and systolic VIM.

Cox proportional hazards regression was performed to assess the association of day-to-day, morning-to-morning and evening-to-evening BPV with all-cause mortality. The proportional hazards assumption of the Cox models was checked using Schoenfeld residuals and the interaction with timedependent variables, no violation was observed. Three models were constructed: model 1 included adjustment for age and gender; model 2 included additional adjustment for vascular score and use of antihypertensive drugs; model 3 additionally included mean systolic BP for the analysis of VIM SBP and mean diastolic BP for the analysis of VIM DBP. The number of events limited including more covariates in the analysis. Imputed data for vascular score was used in the Cox models and pooled hazard ratios were given. First, VIM and CV were modelled as a continuous variable, and hazard ratios are reported per unit increase. Models were constructed using both systolic and diastolic BPV. Next, systolic and diastolic VIM were divided into tertiles. KaplanMeier function estimated cumulative all-cause mortality across tertiles of VIM, and differences between tertiles were assessed using the log-rank test.

A secondary analysis restricted to participants diagnosed with dementia was conducted. Two Cox models were constructed to assess the association of VIM with mortality: model 1 included adjustment for age and gender; and model 2 additionally included mean systolic or diastolic BP.
Furthermore, separate Cox models were performed after 1,3 , and 5 years follow-up to evaluate the prognostic value of VIM at different lengths of follow-up. Participants with a follow-up longer than the period of interest were censored. The same models were used as for the analysis of patients with dementia. A $p$ value $<0.05$ was considered statistically significant. Analyses were performed using IBM SPSS Statistics 25.0 (SPSS, Inc., Chicago, IL, USA) and Stata 16 (Stata Corporation, College Station, TX, USA).

\section{RESULTS}

\section{Baseline characteristics of participants}

315 patients performed HBPM. Of these, 279 obtained $\geq 8$ duplicate measurements and were enrolled in the analyses. We had complete BP datasets (12 measurements) in 129 out of 279 patients (46\%), and 236 patient $(85 \%)$ performed at least 10 measurements. The median number of measurements performed (11, interquartile range 10-12) did not differ between those who died and those who did not die, and there was also no difference among the patients when split by cognitive diagnosis. Additionally, 289 participants obtained $\geq 4$ morning measurements and $267 \geq 4$ evening measurements. Table 1 shows the baseline characteristics of the total study sample and stratified by event status (alive/deceased). Mean age of the study population was $73.2 \pm 8.6$ years and $56.3 \%$ were male. Dementia was diagnosed in 97 (34.8\%) and mild cognitive impairment in 94 (33.7\%) participants. The dementia subtypes that were present in the sample were: Alzheimer's disease (52), vascular dementia (17), mixed dementia (17), unknown origin (4), and other (7).

\section{Blood pressure values}

Mean SBP and DBP were $139.0 \pm 16.4 \mathrm{mmHg}$ and $78.7 \pm 9.3 \mathrm{mmHg}$ respectively, mean day-to-day systolic VIM was $10.2 \pm 3.8$. Morning-to-morning and evening-to-evening systolic VIM were $8.0 \pm 3.4$ and $9.6 \pm 4.3$ respectively (see Supplementary Table 1 ). $\mathrm{CV}$ measures and BP values stratified by cognitive status are found in Supplementary Tables 2 and 3 respectively. Paired samples $T$-test showed that evening-to-evening VIM was higher than morning-to-morning, for both systolic VIM (mean difference $=1.58,95 \%$-CI $1.00-2.15)$ and diastolic VIM (mean difference $=0.91$, 95\%-CI $0.51-1.31$ ), 
Table 1

Characteristics of the study sample and stratified by event status (alive/deceased)

\begin{tabular}{|c|c|c|c|c|c|}
\hline Variable & $\begin{array}{c}\text { Total } \\
\text { sample }\end{array}$ & Alive & Deceased & $\begin{array}{c}\text { Missing } \\
\text { values (\%) }\end{array}$ & $p$-trend \\
\hline $\mathrm{N}$ & 279 & 227 & $52(18.6 \%)$ & & \\
\hline Age (y) & $73 \pm 9$ & $72 \pm 8.5$ & $78.6 \pm 6.6$ & 0 & $<0.001$ \\
\hline Sex (\%male $)$ & $56 \%$ & $54.2 \%$ & $65.4 \%$ & 0 & 0.142 \\
\hline Education level & & & & 0 & 0.706 \\
\hline Low & $5.4 \%$ & $4.8 \%$ & $7.7 \%$ & & \\
\hline Medium & $30.4 \%$ & $30.8 \%$ & $28.8 \%$ & & \\
\hline High & $64.2 \%$ & $64.3 \%$ & $63.5 \%$ & & \\
\hline Follow-up (y) & $3.2 \pm 1.7$ & $3.3 \pm 1.7$ & $2.8 \pm 1.5$ & 0 & 0.018 \\
\hline Current smoking & $11.8 \%$ & $12.3 \%$ & $9.6 \%$ & $2.5 \%$ & 0.572 \\
\hline Alcohol use & $64.2 \%$ & $66.5 \%$ & $53.8 \%$ & $7.5 \%$ & 0.039 \\
\hline (Chronic) heart failure & $4.3 \%$ & $2.6 \%$ & $11.5 \%$ & 0 & 0.004 \\
\hline Coronary heart disease & $22.2 \%$ & $18.5 \%$ & $38.5 \%$ & 0 & 0.002 \\
\hline Cardiac arrythmias & $16.1 \%$ & $13.2 \%$ & $28.8 \%$ & 0 & 0.006 \\
\hline Peripheral artery disease & $6.8 \%$ & $5.7 \%$ & $11.5 \%$ & 0 & 0.133 \\
\hline Cerebrovascular disease & $16.8 \%$ & $14.5 \%$ & $26.9 \%$ & 0 & 0.031 \\
\hline Vascular score & $1.07 \pm 1.06$ & $0.97 \pm 0.92$ & $1.51 \pm 1.46$ & $2.5 \%$ & 0.015 \\
\hline Diabetes mellitus & $17.6 \%$ & $17.2 \%$ & $19.2 \%$ & 0 & 0.726 \\
\hline Body mass index (kg/m2) & $26.4 \pm 4.3$ & $26.8 \pm 4.4$ & $24.6 \pm 3.4$ & $6.8 \%$ & 0.001 \\
\hline Hypertension* & $57.7 \%$ & $55.5 \%$ & $67.3 \%$ & 0 & 0.120 \\
\hline Antihypertensives & $54.5 \%$ & $51.5 \%$ & $67.3 \%$ & 0 & 0.039 \\
\hline Statin use & $40.9 \%$ & $40.5 \%$ & $42.3 \%$ & 0 & 0.814 \\
\hline Anticoagulants/anti platelet aggregation & $41.9 \%$ & $39.2 \%$ & $53.8 \%$ & 0 & 0.054 \\
\hline Cognitive diagnosis, $\mathrm{N}$ & & & & 0 & $<0.001$ \\
\hline Dementia, any type & 97 & 67 & 30 & & \\
\hline Mild cognitive impairment & 94 & 75 & 19 & & \\
\hline Subjective cognitive impairment & 71 & 68 & 3 & & \\
\hline Other** & 17 & 17 & 0 & & \\
\hline
\end{tabular}

Results are presented as mean \pm standard deviation or as a number (percentage). *Defined using home blood pressure measurements: mean systolic blood pressure $\geq 135$ and/or mean diastolic blood pressure $\geq 85 \mathrm{mmHg}$. **Neurological or psychiatric diagnosis.
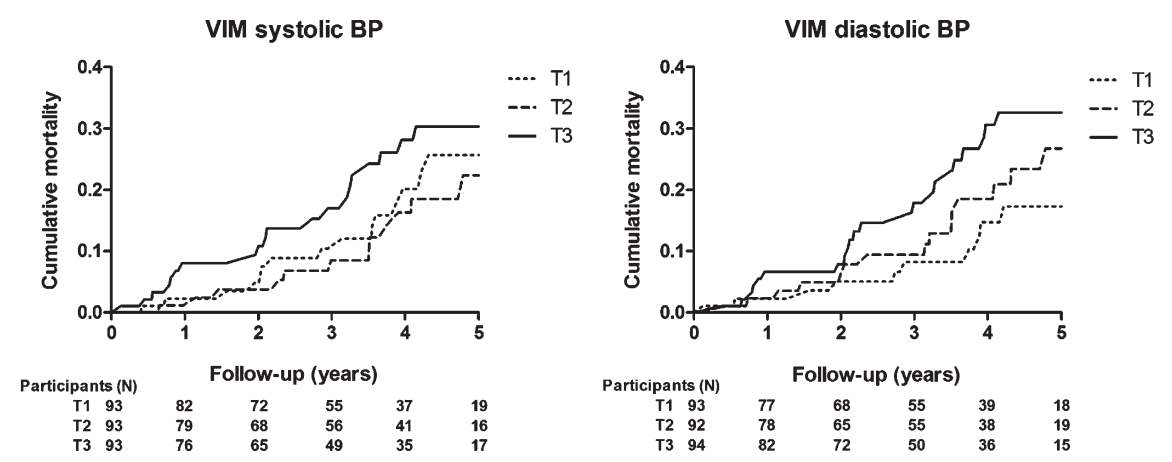

Fig. 1. Kaplan-Meier cumulative all-cause mortality estimates across tertiles of day-to-day blood pressure variability; VIM of systolic blood pressure (left) and diastolic blood pressure (right). T1 to T3 indicate ascending tertiles; cut-off points were 8.03 and 11.19 for systolic and 4.59 and 6.62 for diastolic BP. Participants $(\mathrm{N})$ represents the number at risk during follow-up. VIM, variation independent of the mean; BP, blood pressure.

whereas mean SBP and DBP were higher in the morning. Higher systolic VIM was significantly associated with female sex, older age, and higher vascular score. Systolic VIM was higher in patients with dementia compared to participants with MCI or subjective cognitive impairment, but not for participants with other diagnoses (see Supplementary Table 3).

\section{Analyses of all-cause mortality}

Follow-up ended on December 3, 2019 and mean follow-up time was $3.2 \pm 1.7$ years (range 0.1-5.9). During follow-up, 52 deaths occurred. Cumulative all-cause mortality did not differ across tertiles of the distributions of day-to-day VIM (Fig. 1; 
Table 2

The association between VIM and all-cause mortality

\begin{tabular}{|c|c|c|c|c|c|c|c|c|}
\hline \multirow[t]{2}{*}{ Predictor } & \multirow{2}{*}{$\begin{array}{c}\text { Unadjusted } \\
\text { HR }(95 \% \mathrm{CI})\end{array}$} & \multicolumn{3}{|c|}{ Model 1} & \multirow{2}{*}{$\begin{array}{c}\text { Model } 2 \\
\text { HR }(95 \% \mathrm{CI})^{*}\end{array}$} & \multicolumn{3}{|c|}{ Model 3} \\
\hline & & $p$ & HR $(95 \% \mathrm{CI})$ & $p$ & & $p$ & HR $(95 \% \mathrm{CI})^{*}$ & $p$ \\
\hline \multicolumn{9}{|l|}{ Day-to-day } \\
\hline VIM SBP & $1.03(0.96-1.10)$ & 0.389 & $1.01(0.94-1.08)$ & 0.881 & $0.99(0.92-1.06)$ & 0.771 & $0.99(0.92-1.06)$ & 0.770 \\
\hline VIM DBP & $1.10(0.99-1.21)$ & 0.071 & $1.06(0.95-1.18)$ & 0.304 & $1.04(0.93-1.16)$ & 0.522 & $1.04(0.93-1.17)$ & 0.517 \\
\hline \multicolumn{9}{|c|}{ Morning-to-morning } \\
\hline VIM SBP & $1.09(1.01-1.17)$ & 0.02 & $1.09(1.00-1.17)$ & 0.04 & $1.10(1.01-1.19)$ & 0.032 & $1.09(1.01-1.18)$ & 0.033 \\
\hline VIM DBP & $1.10(1.00-1.20)$ & 0.04 & $1.07(0.97-1.17)$ & 0.167 & $1.08(0.98-1.19)$ & 0.131 & $1.08(0.99-1.18)$ & 0.132 \\
\hline \multicolumn{9}{|c|}{ Evening-to-evening } \\
\hline VIM SBP & $1.03(0.97-1.09)$ & 0.386 & $1.02(0.95-1.08)$ & 0.625 & $1.01(0.95-1.08)$ & 0.773 & $1.01(0.95-1.07)$ & 0.822 \\
\hline VIM DBP & $1.02(0.92-1.12)$ & 0.761 & $1.01(0.91-1.11)$ & 0.900 & $1.00(0.90-1.10)$ & 0.951 & $1.00(0.90-1.10)$ & 0.956 \\
\hline
\end{tabular}

Hazard ratios for all-cause mortality for each unit increase in systolic or diastolic VIM. Model 1: adjusted for age and sex. Model 2: model $1+$ vascular score and use of antihypertensive treatment. Model 3: model $2+$ mean systolic blood pressure (for models with VIM SBP as the outcome) or mean diastolic blood pressure (for models with VIM DBP as the outcome). *Pooled hazard ratios after multiple imputation. BPV, blood pressure variability; VIM, variation independent of the mean; HR, hazard ratio; SBP, systolic blood pressure; DBP, diastolic blood pressure.
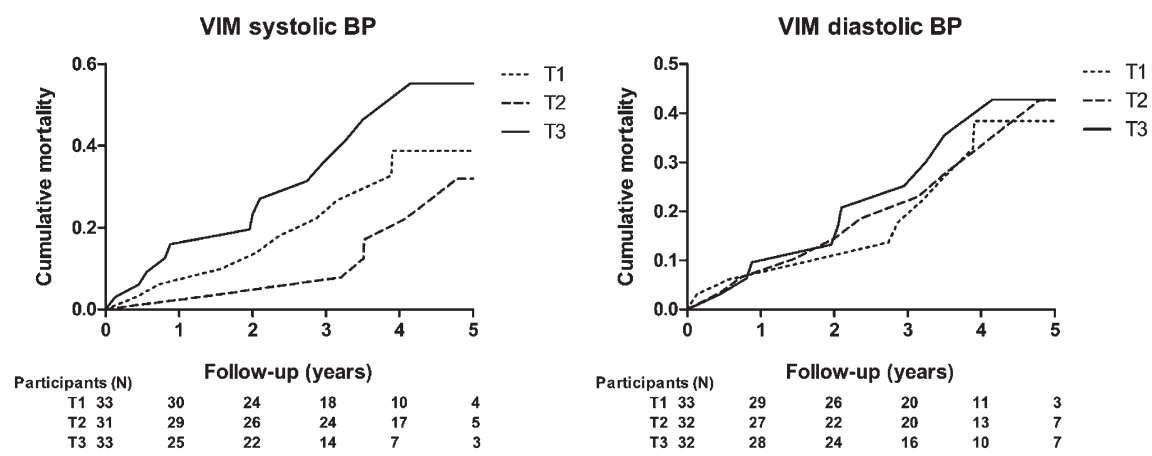

Fig. 2. Kaplan-Meier cumulative all-cause mortality estimates across tertiles of day-to-day blood pressure variability for participants with dementia; VIM of systolic blood pressure (left) and diastolic blood pressure (right). T1 to T3 indicate ascending tertiles; cut-off points were 8.78 and 11.78 for systolic and 4.91 and 6.96 for diastolic BP. Participants $(\mathrm{N})$ represents the number at risk during follow-up. VIM, variation independent of the mean; BP, blood pressure.

log-rank test VIM SBP $p=0.22$, VIM DBP $p=0.10$ ). Table 2 shows the hazard ratios for all-cause mortality for each unit increase in VIM. Systolic and diastolic VIM were not associated with all-cause mortality. However, both systolic and diastolic morning-to-morning VIM were associated with a higher risk for mortality, with an unadjusted HR of 1.09 (95\%-CI 1.01-1.17, $p=0.02)$ and $1.10(95 \%$-CI $1.00-1.20, p=0.04)$ respectively. After adjustment, only systolic morning-to-morning VIM remained significant (HR $1.09 \quad(95 \%$-CI $1.01-1.18, p=0.03)$ ) in the fully adjusted model. Evening-to-evening VIM did not show an association with all-cause mortality. Analyses with CV showed similar results (Supplementary Table 4). A complete-case analyses without participants with imputed data was comparable (Supplementary Table 5).

\section{Analysis of patients with dementia}

In patients with dementia, cumulative incidence for all-cause mortality differed across tertiles of the distributions of systolic VIM, but not for diastolic VIM (Fig. 2; log-rank test VIM SBP $p=0.042$, VIM DBP $p=0.888$ ). Table 3 presents hazard ratios for all-cause mortality for each unit increase in VIM. As with the total group, VIM in both SBP and DBP was not associated with mortality, although a different trend is shown with a higher HR. In the fully adjusted model, HR was 1.07 (95\%-CI 0.99-1.16, $p=0.104$ ) for systolic SBP. Throughout the models, morning-tomorning VIM showed a higher HR per unit increase, although this was marginal. In this subgroup, systolic evening-to-evening VIM was associated with a higher risk for mortality, with a HR of 1.09 (95\%-CI $1.01-1.17, p=0.030$ ) in both adjusted models. 
Table 3

The association between VIM and all-cause mortality, in patients with dementia

\begin{tabular}{|c|c|c|c|c|c|c|}
\hline \multirow[t]{2}{*}{ Predictor } & \multirow{2}{*}{$\begin{array}{c}\text { Unadjusted } \\
\text { HR }(95 \% \mathrm{CI})\end{array}$} & \multirow[b]{2}{*}{$p$} & \multicolumn{2}{|l|}{ Model 1} & \multicolumn{2}{|l|}{ Model 2} \\
\hline & & & HR $(95 \% \mathrm{CI})$ & $p$ & HR $(95 \% \mathrm{CI})$ & $p$ \\
\hline \multicolumn{7}{|l|}{ Day-to-day } \\
\hline VIM SBP & $1.07(0.98-1.15)$ & 0.117 & $1.07(0.98-1.16)$ & 0.116 & $1.07(0.99-1.16)$ & 0.104 \\
\hline VIM DBP & $1.07(0.94-1.22)$ & 0.287 & $1.08(0.94-1.24)$ & 0.268 & $1.08(0.94-1.23)$ & 0.295 \\
\hline \multicolumn{7}{|c|}{ Morning-to-morning } \\
\hline VIM SBP & $1.08(0.99-1.18)$ & 0.090 & $1.09(0.99-1.20)$ & 0.075 & $1.09(0.99-1.20)$ & 0.075 \\
\hline VIM DBP & $1.02(0.91-1.14)$ & 0.712 & $1.02(0.91-1.14)$ & 0.777 & $1.00(0.89-1.13)$ & 0.952 \\
\hline \multicolumn{7}{|c|}{ Evening-to-evening } \\
\hline VIM SBP & $1.09(1.01-1.17)$ & 0.032 & $1.09(1.01-1.17)$ & 0.030 & $1.09(1.01-1.17)$ & $\mathbf{0 . 0 3 0}$ \\
\hline VIM DBP & $1.03(0.92-1.16)$ & 0.574 & $1.04(0.93-1.17)$ & 0.492 & $1.04(0.92-1.17)$ & 0.527 \\
\hline
\end{tabular}

Hazard ratios for all-cause mortality for each unit increase in systolic or diastolic VIM, in patients with dementia. Model 1: adjusted for age and sex. Model 2: model $1+$ mean systolic blood pressure (for models with VIM SBP as the outcome) or mean diastolic blood pressure (for models with VIM DBP as the outcome). BPV, blood pressure variability; VIM, variation independent of the mean; HR, hazard ratio; SBP, systolic blood pressure; DBP, diastolic blood pressure.

Table 4

The association between day-to-day VIM and all-cause mortality after 1, 3, and 5 years follow-up

\begin{tabular}{|c|c|c|c|c|c|c|c|}
\hline \multirow[t]{2}{*}{ Follow-up (y) } & \multirow[t]{2}{*}{ Predictor } & \multirow{2}{*}{$\begin{array}{c}\text { Unadjusted } \\
\text { HR }(95 \% \mathrm{CI})\end{array}$} & \multirow[b]{2}{*}{$p$} & \multicolumn{2}{|l|}{ Model 1} & \multicolumn{2}{|l|}{ Model 2} \\
\hline & & & & HR $(95 \% \mathrm{CI})$ & $p$ & HR $(95 \% \mathrm{CI})$ & $p$ \\
\hline & Day-to-day & & & & & & \\
\hline \multirow[t]{2}{*}{1} & VIM SBP & $1.14(1.00-1.28)$ & 0.043 & $1.12(0.98-1.27)$ & 0.102 & $1.12(0.98-1.27)$ & 0.105 \\
\hline & VIM DBP & $1.15(0.92-1.44)$ & 0.211 & $1.11(0.86-1.42)$ & 0.423 & $1.10(0.86-1.41)$ & 0.441 \\
\hline \multirow[t]{2}{*}{3} & VIM SBP & $1.05(0.96-1.14)$ & 0.292 & $1.04(0.95-1.14)$ & 0.411 & $1.04(0.95-1.14)$ & 0.402 \\
\hline & VIM DBP & $1.12(0.98-1.29)$ & 0.111 & $1.10(0.95-1.27)$ & 0.221 & $1.10(0.95-1.28)$ & 0.219 \\
\hline \multirow[t]{2}{*}{5} & VIM SBP & $1.03(0.96-1.11)$ & 0.358 & $1.02(0.95-1.10)$ & 0.593 & $1.02(0.95-1.10)$ & 0.585 \\
\hline & VIM DBP & $1.12(1.01-1.24)$ & 0.035 & $1.09(0.98-1.22)$ & 0.115 & $1.09(0.98-1.22)$ & 0.124 \\
\hline
\end{tabular}

Hazard ratios for all-cause mortality for each unit increase in systolic or diastolic day-to-day VIM after 1, 3, and 5 years follow-up. Model 1: adjusted for age and sex. Model 2: model $1+$ mean systolic blood pressure (for models with VIM SBP as the outcome) or mean diastolic blood pressure (for models with VIM DBP as the outcome). BPV, blood pressure variability; VIM, variation independent of the mean; HR, hazard ratio; SBP, systolic blood pressure; DBP, diastolic blood pressure.

Table 5

The association between morning-to-morning VIM and all-cause mortality after 1, 3, and 5 years follow-up

\begin{tabular}{|c|c|c|c|c|c|c|c|}
\hline \multirow[t]{2}{*}{ Follow-up (y) } & \multirow[t]{2}{*}{ Predictor } & \multirow{2}{*}{$\begin{array}{c}\text { Unadjusted } \\
\text { HR }(95 \% \mathrm{CI}) \\
\end{array}$} & \multirow[b]{2}{*}{$p$} & \multicolumn{2}{|l|}{ Model 1} & \multicolumn{2}{|l|}{ Model 2} \\
\hline & & & & HR $(95 \% \mathrm{CI})$ & $p$ & HR $(95 \% \mathrm{CI})$ & $p$ \\
\hline \multirow[t]{2}{*}{1} & VIM SBP & $1.22(1.07-1.38)$ & 0.002 & $1.22(1.07-1.38)$ & 0.003 & $1.21(1.06-1.38)$ & 0.004 \\
\hline & VIM DBP & $1.22(1.03-1.44)$ & 0.018 & $1.20(1.01-1.43)$ & 0.038 & $1.21(1.01-1.44)$ & 0.039 \\
\hline \multirow[t]{2}{*}{3} & VIM SBP & $1.09(0.99-1.20)$ & 0.066 & $1.10(0.99-1.21)$ & 0.084 & $1.09(0.99-1.21)$ & 0.091 \\
\hline & VIM DBP & $1.15(1.02-1.29)$ & 0.021 & $1.14(1.00-1.29)$ & 0.044 & $1.14(1.00-1.29)$ & 0.044 \\
\hline \multirow[t]{2}{*}{5} & VIM SBP & $1.07(0.99-1.15)$ & 0.077 & $1.07(0.98-1.16)$ & 0.118 & $1.07(0.98-1.16)$ & 0.115 \\
\hline & VIM DBP & $1.10(1.01-1.21)$ & 0.034 & $1.08(0.98-1.19)$ & 0.113 & $1.08(0.98-1.19)$ & 0.117 \\
\hline
\end{tabular}

Hazard ratios for all-cause mortality for each unit increase in systolic or diastolic morning-to-morning VIM after 1, 3 and 5 years follow-up. Model 1: adjusted for age and sex. Model 2: model 1+ mean systolic blood pressure (for models with VIM SBP as the outcome) or mean diastolic blood pressure (for models with VIM DBP as the outcome). BPV, blood pressure variability; VIM, variation independent of the mean; HR, hazard ratio; SBP, systolic blood pressure; DBP, diastolic blood pressure.

\section{Prognostic value over time}

Table 4 displays the association between dayto-day VIM and mortality after 1,3 , and 5 years follow-up. For systolic VIM, the HR seemed to be highest after 1 year follow-up (fully adjusted $\mathrm{HR}=$ $1.12,95 \%$-CI $0.98-1.27, p=0.105$ ), and decreased over time, although this was not significant. The
HR for diastolic VIM remained stable throughout the years. For morning-to-morning VIM, the HR was highest after 1 year for both systolic and diastolic VIM, which is shown in Table 5. In the fully adjusted model, the HR for systolic and diastolic morning-to-morning VIM was $1.21(95 \%$-CI $1.06-1.38, p=0.004)$ and $1.21(95 \%$-CI 1.01-1.44, $p=0.039$ ) respectively. After 3 and 5 years follow-up, 
the HR decreased, but remained $>1.00$ with marginal significance. (Data evening-to-evening VIM is shown in Supplementary Table 6).

\section{DISCUSSION}

This study examined the association of day-to-day BPV with all-cause mortality in a memory clinic population. The key findings are as follows: 1) overall systolic and diastolic day-to-day BPV were not associated with all-cause mortality in this population; 2) increased systolic morning-to-morning BPV, however, was associated with a higher risk for mortality; 3 ) in the analysis of patients with dementia, eveningto-evening BPV was associated with mortality, while morning-to-morning and day-to-day BPV showed potential associations; 4) hazard ratios and predictive value of systolic day-to-day and morning-to-morning BPV seemed to decrease for longer survival time.

Previous studies assessing the association between BPV and mortality have shown conflicting results [16-19, 43-45]. The majority of these studies used visit-to-visit BPV, which is assessed across multiple visits to the clinic. Day-to-day BPV measured at home is likely to have a better clinical applicability. It provides information on the consistency of $\mathrm{BP}$ within a shorter timeframe, is more reproducible, offers better prognostic value [20] and out-of-office measurement are generally more representative for actual BP than office measurements $[10,21]$. 24$\mathrm{h}$ ambulatory $\mathrm{BP}$ monitoring (ABPM) is another method to measure BPV. However, this is the only method of measurement which takes into account BP both at rest and during daily activities, leading to a higher range of blood pressures depending on the activities a person does during the day. Only three studies, of which two used the same Japanese cohort, investigated the association of home-measured dayto-day BPV with mortality, and showed a modest association [22-24]. Furthermore, the first Osahama study divided causes of mortality into cardiovascular and non-cardiovascular mortality, which showed a comparable HR. Moreover, both the Finn-home and the second Osahama study reported that systolic morning-to-morning BPV was associated with mortality, while systolic evening-to-evening BPV was not [23, 24].

Similar to these studies, we found an association between increased morning-to-morning BPV and all-cause mortality. However, we did not find an association between day-to-day BPV and mortality. There are several differences between our study and previous studies, which limit their comparability. Both the Finn-home and Osahama cohorts consist of a general, relatively healthy, middle aged population or with a wide age. The Japanese Osahama cohort represents an ethnically different population, with a lower incidence CVD [46]. Furthermore, only nonduplicated measurements were used, which might increase the possibility that BPV is affected by measurement error. The Finnish study used the SD as a measure for BPV, which is known to be correlated to the mean. Both studies included a younger population compared to our study. Older age is associated with higher BPV [16, 47], as was the case in this study. In older age, frailty increases as a consequence of age-related decline in multiple physiological systems, leading to vulnerability to minor stressors [48]. Physical resilience, which is the ability of an organism to respond to physical stress that disrupts normal homeostasis, is decreased in older adults [49]. Therefore, a higher day-to-day BPV in older people could be a reflection of this lower resilience. Thus, some authors have proposed a larger prognostic value of BPV among older adults compared to younger and middle aged adults [16]. Others contradict this suggestion, stating that the association between BPV and mortality or other adverse events does not correspondingly increase in older populations [33, 50]. This study did not aim to distinguish between different categories of age, but it is tempting to hypothesize that in older persons more competing mechanisms are present compared to younger persons, leading to a lower or no association with mortality compared to study populations including middle-aged adults.

This study had a shorter follow-up period compared to the previous studies (mean follow-up 3.2 years versus 11.9 and 7.8 years). A study examining visit-to-visit BPV and mortality found that BPV was predictive for mortality in the longer (7 years), but not in the short follow-up (3 years) [33]. However, results for visit-to-visit BPV cannot be compared with day-to-day BPV, because of the different timeframe and setting. Moreover, it is proposed that different measures of BPV are weakly correlated and not interchangeable [51, 52]. In contrast, in the Osahama study the predictive value of BPV for non-cardiovascular mortality weakened after censoring the first 2 years [22]. In our study, the association between BPV and mortality appeared to be higher after the first year, compared to 3 or 5 years of followup, although this was only significant for the morning measurements and mostly for SBP. This might indicate a more refined predictive value for day-to-day 
BPV for the short term. An explanation could be that over time, changes can occur in a participant's health status, leading to competing mechanisms. Another possibility might be reverse causation; high day-today BPV could be an indication of underlying disease or an expression of dysfunction of the cardiovascular system, leading to adverse outcomes in the short term. This finding regarding different associations during follow-up should be interpreted with caution however, and ought to be considered explorative.

Bearing in mind that this area of research lacks a gold standard for BPV, the differences in observations between studies may also endorse the need for standardized methods to quantify BPV and the importance of replicating research results.

\section{Morning-to-morning BPV}

Returning to our finding that morningto-morning BPV is associated with all-cause mortality. Due to the short assessment window and small sample size of this study, the results should be interpreted with caution. However, it is interesting to speculate about possible explanations for this finding. Determinants and correlates of BPV are still under investigation and the mechanisms underpinning BPV remain speculative. Different types of BPV have been associated with multiple predictors of cardiovascular events, such as increased left ventricular mass index and arterial stiffness [53-56] and more pronounced hypertension-mediated target organ damage, independent of mean BP [57].

The morning hours are characterized by the highest incidence of cardiovascular events [58-60], which has been linked to increased thrombocyte aggregability [61] and activation of the sympathetic nervous system in the morning [60, 62]. Another concept is the so-called morning surge: a disproportional high peak in BP after waking up. Sudden activation of the sympathetic nervous system is seen as the primary mediator [59], and this morning surge is proposed to be a risk factor for cardiovascular events [59, 63]. For example, it may disrupt vulnerable plaques causing rupture and thrombosis [60]. On the other hand, higher BPV could also reflect a decreased adaptability to this stressor in the morning, due to a lower resilience. Therefore, higher morningto-morning BPV might reflect the varying presence of a morning surge and decreased adaptability to this stressor, increased activity of the sympathetic nervous system, arterial stiffness, and other predictors of (fatal) cardiovascular events.

\section{Analysis of patients with dementia}

Analysis of patients with dementia showed a trend with a higher hazard ratio for mortality compared to the total study sample. Patients suffering from dementia are more likely to become frail over time and have a lower resilience compared to older persons without dementia $[64,65]$, which could result in a larger impact of high BPV on adverse outcomes. They might be more susceptible to fluctuation in BP due to decreased adaptability to stressors. This hypothesis should be further examined in future research. It would also be interesting to add BPV to a prognostic cardiovascular model for patients with dementia and to examine the added value of this predictor. This could be valuable in patients with a high cardiovascular burden, since there are indications that $\mathrm{BPV}$ is a stronger predictor in subjects at high cardiovascular risk, while the contribution of BPV to risk stratification is low in subjects without cardiovascular comorbidities $[66,67]$.

\section{Strengths and limitations}

This study has several strengths and limitations. The use of duplicate BP measurements, twice a day for 7 consecutive days, ensured a high degree of reproducibility and made the measurements less prone to fluctuation caused by external factors such as change in lifestyle or environment. Although participants (and in most cases an informal caregiver) received individual instruction on how to perform the measurements correctly, they performed HBPM unguided, making it not possible to ensure adherence to instructions. However, the use of a validated device with a pre-programmed measurement schedule and automatic saving of BP measurements limited user errors and reporting bias. Furthermore, patient characteristics were assessed at baseline and no additional information was available, such as a change in medication or comorbidities during follow-up, which is a limitation. Despite this, BP was measured at baseline in this study, and not overlapping with follow-up, as is the case in some previous research [68]. Additionally, the use of VIM provided a reliable measure for BPV, uncorrelated to the mean. Patients with lower cognitive functioning were less likely to agree to perform HBPM, leading to a selection bias. Still, the study sample included a large diversity in cognitive functioning. Other limitations include the small sample size and number of events. The sample size of this study was too small to look at dementia and MCI 
subtypes, and analysis of morning-to-morning VIM might have been prone to multiplicity. Lastly, the setting of an outpatient memory clinic does not allow direct generalization to, e.g., primary care, although the variety in cognitive performance in this sample represents quite a proportion of the general elderly population with cognitive complaints.

\section{Perspectives}

This study is the first to investigate day-to-day BPV and mortality in a population with cognitive impairment. Even though no association between day-to-day BPV and mortality was found, a multitude of studies on (visit-to-visit/day-to-day) BPV are available which share the common finding that higher BPV is modestly associated with mortality and other adverse outcomes. However, the methods used are heterogeneous and a gold standard is lacking. Thus, more research is needed into the optimal schedule for measuring BPV and how to quantify variability in routine practice. Besides, future research should address to the effects of BPV in patients with dementia, and to the association of morning-to-morning BPV with adverse outcomes since this measure seems promising.

Improved knowledge concerning this subject could have several clinical implications for the future. Dayto-day BPV might be used to determine the resilience of older, cognitively impaired, patients. It is proposed that dynamic measures, i.e., measures with a time scale, can be used to forecast resilience in older persons [69]. Day-to-day BPV is a dynamic measure and could be of use to predict chances for recovery, for example prior to major surgery. Moreover, little is known about the longitudinal course of an individual with dementia, in which BPV might play a role. Should BPV prove to have a causal association with progression of dementia or mortality, BP management in the future should not only focus on lowering mean BP, which is the current standard [10], but also on reducing large fluctuations. It is suggested that certain antihypertensive drugs, such as calcium channel blockers, lower both mean BP and fluctuations, while others may increase fluctuations [70-73]. However, the impact of BPV lowering on organ damage or dementia prognosis is unknown. At this moment, convincing evidence is still absent and fundamental questions remain unanswered, including the optimal variability index and measurement schedule, and the threshold that defines increased BPV. Further research is needed to refine understanding of the causes and consequences of dayto-day and morning-to-morning BPV in older persons with cognitive impairment, but also in other populations. Until this knowledge becomes available, clinicians and researchers should remain aware of the associations with, and implications of, variability in BP.

\section{CONCLUSION}

In this study, day-to-day BPV was not associated with all-cause mortality in a memory clinic population, while morning-to-morning BPV was. In addition, hazard ratios seemed to be higher in patients with dementia and after a shorter follow-up period. However, results should be interpreted with caution and there is still a lack of clarity, hence future research is warranted to clarify the association of all BPV components with mortality in older adults with cognitive impairment.

\section{ACKNOWLEDGMENTS}

We are grateful to all study participants and their caregivers for their time and effort. We thankfully acknowledge all individuals for the recruitment and gathering of the data. The study was funded by the Dutch Alzheimer Society (grant number WE.092015-03).

Authors' disclosures available online (https:// www.j-alz.com/manuscript-disclosures/21-5002r1).

\section{SUPPLEMENTARY MATERIAL}

The supplementary material is available in the electronic version of this article: https://dx.doi.org/ 10.3233/JAD-215002.

\section{REFERENCES}

[1] Lawes CM, Vander Hoorn S, Rodgers A, International Society of Hypertension (2008) Global burden of bloodpressure-related disease, 2001. Lancet 371, 1513-1518.

[2] Kjeldsen SE (2018) Hypertension and cardiovascular risk: General aspects. Pharmacol Res 129, 95-99.

[3] Zheng LQ, Li J, Sun ZQ, Zhang XG, Hu DY, Sun YX (2015) Relationship of blood pressure with mortality and cardiovascular events among hypertensive patients aged $\geq 60$ years in rural areas of China: A Strobe-compliant study. Medicine 94, e1551.

[4] Iulita MF, Girouard H (2017) Treating hypertension to prevent cognitive decline and dementia: Re-opening the debate. Adv Exp Med Biol 956, 447-473. 
[5] Livingston G, Sommerlad A, Orgeta V, Costafreda SG, Huntley J, Ames D, Ballard C, Banerjee S, Burns A, CohenMansfield J, Cooper C, Fox N, Gitlin LN, Howard R, Kales HC, Larson EB, Ritchie K, Rockwood K, Sampson EL, Samus Q, Schneider LS, Selbaek G, Teri L, Mukadam N (2017) Dementia prevention, intervention, and care. Lancet 390, 2673-2734.

[6] Qiu C, Winblad B, Fratiglioni L (2005) The age-dependent relation of blood pressure to cognitive function and dementia. Lancet Neurol 4, 487-499.

[7] Abete P, Della-Morte D, Gargiulo G, Basile C, Langellotto A, Galizia G, Testa G, Canonico V, Bonaduce D, Cacciatore F (2014) Cognitive impairment and cardiovascular diseases in the elderly. A heart-brain continuum hypothesis. Ageing Res Rev 18, 41-52.

[8] Mossello E, Pieraccioli M, Nesti N, Bulgaresi M, Lorenzi C, Caleri V, Tonon E, Cavallini MC, Baroncini C, Di Bari M, Baldasseroni S, Cantini C, Biagini CA, Marchionni N, Ungar A (2015) Effects of low blood pressure in cognitively impaired elderly patients treated with antihypertensive drugs. JAMA Intern Med 175, 578-585.

[9] Bellew KM, Pigeon JG, Stang PE, Fleischman W, Gardner RM, Baker WW (2004) Hypertension and the rate of cognitive decline in patients with dementia of the Alzheimer type. Alzheimer Dis Assoc Disord 18, 208-213.

[10] Williams B, Mancia G, Spiering W, Agabiti Rosei E, Azizi M, Burnier M, Clement DL, Coca A, de Simone G, Dominiczak A, Kahan T, Mahfoud F, Redon J, Ruilope L, Zanchetti A, Kerins M, Kjeldsen SE, Kreutz R, Laurent S, Lip GYH, McManus R, Narkiewicz K, Ruschitzka F, Schmieder RE, Shlyakhto E, Tsioufis C, Aboyans V, Desormais I, ESC Scientific Document Group (2018) $2018 \mathrm{ESC} / \mathrm{ESH}$ Guidelines for the management of arterial hypertension. Eur Heart J 39, 3021-3104.

[11] Melis RJF, Haaksma ML, Muniz-Terrera G (2019) Understanding and predicting the longitudinal course of dementia. Curr Opin Psychiatry 32, 123-129.

[12] Howard SC, Rothwell PM (2009) Reproducibility of measures of visit-to-visit variability in blood pressure after transient ischaemic attack or minor stroke. Cerebrovasc Dis 28, 331-340.

[13] Rothwell PM, Howard SC, Dolan E, O'Brien E, Dobson JE, Dahlof B, Sever PS, Poulter NR (2010) Prognostic significance of visit-to-visit variability, maximum systolic blood pressure, and episodic hypertension. Lancet 375, 895-905.

[14] Hata Y, Kimura Y, Muratani H, Fukiyama K, Kawano Y, Ashida T, Yokouchi M, Imai Y, Ozawa T, Fujii J, Omae T (2000) Office blood pressure variability as a predictor of brain infarction in elderly hypertensive patients. Hypertens Res 23, 553-560.

[15] Stevens SL, Wood S, Koshiaris C, Law K, Glasziou P, Stevens RJ, McManus RJ (2016) Blood pressure variability and cardiovascular disease: Systematic review and metaanalysis. BMJ 354, i4098.

[16] Muntner P, Shimbo D, Tonelli M, Reynolds K, Arnett DK, Oparil S (2011) The relationship between visit-to-visit variability in systolic blood pressure and all-cause mortality in the general population: Findings from NHANES III, 1988 to 1994. Hypertension 57, 160-166.

[17] Dai L, Song L, Li X, Yang Y, Zheng X, Wu Y, Li C, Zhao H, Wang Y, Wu S, Wang Y (2018) Association of visitto-visit blood pressure variability with the risk of all-cause mortality and cardiovascular events in general population. J Clin Hypertens (Greenwich) 20, 280-288.
[18] Muntner P, Whittle J, Lynch AI, Colantonio LD, Simpson LM, Einhorn PT, Levitan EB, Whelton PK, Cushman WC, Louis GT, Davis BR, Oparil S (2015) Visit-to-visit variability of blood pressure and coronary heart disease, stroke, heart failure, and mortality: A cohort study. Ann Intern Med 163, 329-338.

[19] Suchy-Dicey AM, Wallace ER, Elkind MSV, Aguilar M, Gottesman RF, Rice K, Kronmal R, Psaty BM, Longstreth WT (2013) Blood pressure variability and the risk of allcause mortality, incident myocardial infarction, and incident stroke in the Cardiovascular Health Study. Am J Hypertens 26, 1210-1217.

[20] Niiranen TJ, Hanninen MR, Johansson J, Reunanen A, Jula AM (2010) Home-measured blood pressure is a stronger predictor of cardiovascular risk than office blood pressure: The Finn-Home study. Hypertension 55, 1346-1351.

[21] Parati G, Stergiou GS, Asmar R, Bilo G, de Leeuw P, Imai Y, Kario K, Lurbe E, Manolis A, Mengden T, O’Brien E, Ohkubo T, Padfield P, Palatini P, Pickering T, Redon J, Revera M, Ruilope LM, Shennan A, Staessen JA, Tisler A, Waeber B, Zanchetti A, Mancia G, Monitoring ESHWGoBP (2008) European Society of Hypertension guidelines for blood pressure monitoring at home: A summary report of the Second International Consensus Conference on Home Blood Pressure Monitoring. J Hypertens 26, 1505-1526.

[22] Kikuya M, Ohkubo T, Metoki H, Asayama K, Hara A, Obara T, Inoue R, Hoshi H, Hashimoto J, Totsune K, Satoh H, Imai Y (2008) Day-by-day variability of blood pressure and heart rate at home as a novel predictor of prognosis: The Ohasama study. Hypertension 52, 1045-1050.

[23] Johansson JK, Niiranen TJ, Puukka PJ, Jula AM (2012) Prognostic value of the variability in home-measured blood pressure and heart rate: The Finn-Home Study. Hypertension 59, 212-218.

[24] Asayama K, Kikuya M, Schutte R, Thijs L, Hosaka M, Satoh M, Hara A, Obara T, Inoue R, Metoki H, Hirose T, Ohkubo T, Staessen JA, Imai Y (2013) Home blood pressure variability as cardiovascular risk factor in the population of Ohasama. Hypertension 61, 61-69.

[25] de Heus RAA, Tzourio C, Lee EJL, Opozda M, Vincent AD, Anstey KJ, Hofman A, Kario K, Lattanzi S, Launer LJ, Ma Y, Mahajan R, Mooijaart SP, Nagai M, Peters R, Turnbull D, Yano Y, Consortium VB, Claassen J, Tully PJ (2021) Association between blood pressure variability with dementia and cognitive impairment: A systematic review and meta-analysis. Hypertension 78, 1478-1489.

[26] de Heus RAA, Olde Rikkert MGM, Tully PJ, Lawlor BA, Claassen J, NILVAD Study Group (2019) Blood pressure variability and progression of clinical Alzheimer disease. Hypertension 74, 1172-1180.

[27] Lattanzi S, Luzzi S, Provinciali L, Silvestrini M (2014) Blood pressure variability predicts cognitive decline in Alzheimer's disease patients. Neurobiol Aging 35, 22822287.

[28] O'Caoimh R, Gao Y, Svendrovski A, Illario M, Iaccarino G, Yavuz BB, Kehoe PG, Molloy DW (2019) Effect of visit-to-visit blood pressure variability on cognitive and functional decline in mild to moderate Alzheimer's disease. J Alzheimers Dis 68, 1499-1510.

[29] Lattanzi S, Viticchi G, Falsetti L, Buratti L, Luzzi S, Provinciali L, Silvestrini M (2014) Visit-to-visit blood pressure variability in Alzheimer disease. Alzheimer Dis Assoc Disord 28, 347-351.

[30] Tully PJ, Yano Y, Launer LJ, Kario K, Nagai M, Mooijaart SP, Claassen JAHR, Lattanzi S, Vincent AD, Tzourio C; 
Variability in Blood Pressure and Brain Health Consortium $\dagger$; Variability in Blood Pressure and Brain Health Consortium (2020) Association between blood pressure variability and cerebral small-vessel disease: A systematic review and meta-analysis. J Am Heart Assoc 9, e013841.

[31] Rensma SP, van Sloten TT, Launer LJ, Stehouwer CDA (2018) Cerebral small vessel disease and risk of incident stroke, dementia and depression, and all-cause mortality: A systematic review and meta-analysis. Neurosci Biobehav $\operatorname{Rev}$ 90, 164-173.

[32] Toledo JB, Arnold SE, Raible K, Brettschneider J, Xie SX, Grossman M, Monsell SE, Kukull WA, Trojanowski JQ (2013) Contribution of cerebrovascular disease in autopsy confirmed neurodegenerative disease cases in the National Alzheimer's Coordinating Centre. Brain 136, 2697-2706.

[33] Poortvliet RK, Ford I, Lloyd SM, Sattar N, Mooijaart SP, de Craen AJ, Westendorp RG, Jukema JW, Packard CJ, Gussekloo J, de Ruijter W, Stott DJ (2012) Blood pressure variability and cardiovascular risk in the PROspective Study of Pravastatin in the Elderly at Risk (PROSPER). PLoS One 7, e52438.

[34] de Heus RAA, Reumers SFI, van der Have A, Tumelaire M, Tully PJ, Claassen J (2020) Day-to-day home blood pressure variability is associated with cerebral small vessel disease burden in a memory clinic population. J Alzheimers Dis $\mathbf{7 4 ,}$ 463-472.

[35] de Heus RA, Tumelaire MV, Olde Rikkert MG, Claassen JA (2019) Diagnostic accuracy of office blood pressure compared to home blood pressure in patients with mild cognitive impairment and dementia. Eur J Cardiovasc Nurs 18, 637-642.

[36] Stergiou GS, Giovas PP, Gkinos CP, Patouras JD (2007) Validation of the Microlife WatchBP Home device for self home blood pressure measurement according to the International Protocol. Blood Press Monit 12, 185-188.

[37] Dolan E, O’Brien E (2010) Blood pressure variability: Clarity for clinical practice. Hypertension 56, 179-181.

[38] Personal records database, https://www.government.nl/ topics/personal-data/personal-records-database-brp

[39] Van der Elst W, van Boxtel MP, van Breukelen GJ, Jolles J (2005) Rey's verbal learning test: Normative data for 1855 healthy participants aged 24-81 years and the influence of age, sex, education, and mode of presentation. $J$ Int Neuropsychol Soc 11, 290-302.

[40] Spies PE, Verbeek MM, Sjogren MJ, de Leeuw FE, Claassen JA (2014) Alzheimer biomarkers and clinical Alzheimer disease were not associated with increased cerebrovascular disease in a memory clinic population. Curr Alzheimer Res 11, 40-46.

[41] American Psychiatric Association (2013) Diagnostic and statistical manual of mental disorders, 5th edition, American Psychiatric Association Publishing, Washington, DC.

[42] Albert MS, DeKosky ST, Dickson D, Dubois B, Feldman HH, Fox NC, Gamst A, Holtzman DM, Jagust WJ, Petersen RC, Snyder PJ, Carrillo MC, Thies B, Phelps CH (2011) The diagnosis of mild cognitive impairment due to Alzheimer's disease: Recommendations from the National Institute on Aging-Alzheimer's Association workgroups on diagnostic guidelines for Alzheimer's disease. Alzheimers Dement 7, 270-279.

[43] Schutte R, Thijs L, Liu YP, Asayama K, Jin Y, Odili A, Gu YM, Kuznetsova T, Jacobs L, Staessen JA (2012) Withinsubject blood pressure level-not variability-predicts fatal and nonfatal outcomes in a general population. Hypertension 60, 1138-1147.
[44] Gao S, Hendrie HC, Wang C, Stump TE, Stewart JC, Kesterson J, Clark DO, Callahan CM (2014) Redefined blood pressure variability measure and its association with mortality in elderly primary care patients. Hypertension 64, 45-52.

[45] Hara A, Thijs L, Asayama K, Jacobs L, Wang JG, Staessen JA (2014) Randomised double-blind comparison of placebo and active drugs for effects on risks associated with blood pressure variability in the Systolic Hypertension in Europe trial. PLoS One 9, e103169.

[46] Iso H (2011) A Japanese health success story: Trends in cardiovascular diseases, their risk factors, and the contribution of public health and personalized approaches. EPMA $J \mathbf{2}$, 49-57.

[47] Satoh M, Metoki H, Asayama K, Murakami T, Inoue R, Tsubota-Utsugi M, Matsuda A, Hirose T, Hara A, Obara T, Kikuya M, Nomura K, Hozawa A, Imai Y, Ohkubo T (2019) Age-related trends in home blood pressure, home pulse rate, and day-to-day blood pressure and pulse rate variability based on longitudinal cohort data: The Ohasama Study. J Am Heart Assoc 8, e012121.

[48] Clegg A, Young J, Iliffe S, Rikkert MO, Rockwood K (2013) Frailty in elderly people. Lancet $\mathbf{3 8 1}, 752-762$.

[49] Schorr A, Carter C, Ladiges W (2018) The potential use of physical resilience to predict healthy aging. Pathobiol Aging Age Relat Dis 8, 1403844.

[50] Bilo G, Dolan E, O'Brien E, Facchetti R, Soranna D, Zambon A, Mancia G, Parati G (2020) The impact of systolic and diastolic blood pressure variability on mortality is age dependent: Data from the Dublin Outcome Study. Eur J Prev Cardiol 27, 355-364.

[51] Muntner P, Shimbo D, Diaz KM, Newman J, Sloan RP, Schwartz JE (2013) Low correlation between visit-to-visit variability and 24-h variability of blood pressure. Hypertens Res 36, 940-946.

[52] Abellan-Huerta J, Prieto-Valiente L, Montoro-Garcia S, Abellan-Aleman J, Soria-Arcos F (2018) Correlation of blood pressure variability as measured by clinic, selfmeasurement at home, and ambulatory blood pressure monitoring. Am J Hypertens 31, 305-312.

[53] Schillaci G, Bilo G, Pucci G, Laurent S, Macquin-Mavier I, Boutouyrie P, Battista F, Settimi L, Desamericq G, Dolbeau G, Faini A, Salvi P, Mannarino E, Parati G (2012) Relationship between short-term blood pressure variability and large-artery stiffness in human hypertension: Findings from 2 large databases. Hypertension 60, 369-377.

[54] Mancia G, Parati G (2003) The role of blood pressure variability in end-organ damage. J Hypertens Suppl 21, S17-23.

[55] Ishiyama Y, Hoshide S, Kanegae H, Kario K (2020) Increased arterial stiffness amplifies the association between home blood pressure variability and cardiac overload: The J-HOP Study. Hypertension 75, 1600-1606.

[56] Matsui Y, Ishikawa J, Eguchi K, Shibasaki S, Shimada K, Kario K (2011) Maximum value of home blood pressure: A novel indicator of target organ damage in hypertension. Hypertension 57, 1087-1093.

[57] Mancusi C, Trimarco V, Losi MA, Canciello G, Morisco C, Manzi MV, Arnone MI, Fucile I, de Simone G, Izzo R, De Luca N, Trimarco B (2021) Impact of visit-tovisit blood pressure variability on hypertensive-mediated target organ damage and future cardiovascular events: The Campania salute network. J Hypertens 39, 18521858.

[58] Muller JE (1999) Circadian variation in cardiovascular events. Am J Hypertens 12, 35S-42S. 
[59] Bilo G, Grillo A, Guida V, Parati G (2018) Morning blood pressure surge: Pathophysiology, clinical relevance and therapeutic aspects. Integr Blood Press Control 11, 47-56.

[60] Atkinson G, Jones H, Ainslie PN (2010) Circadian variation in the circulatory responses to exercise: Relevance to the morning peaks in strokes and cardiac events. Eur J Appl Physiol 108, 15-29.

[61] Tofler GH, Brezinski D, Schafer AI, Czeisler CA, Rutherford JD, Willich SN, Gleason RE, Williams GH, Muller JE (1987) Concurrent morning increase in platelet aggregability and the risk of myocardial infarction and sudden cardiac death. $N$ Engl J Med 316, 1514-1518.

[62] Dodt C, Breckling U, Derad I, Fehm HL, Born J (1997) Plasma epinephrine and norepinephrine concentrations of healthy humans associated with nighttime sleep and morning arousal. Hypertension 30, 71-76.

[63] Amici A, Cicconetti P, Sagrafoli C, Baratta A, Passador P, Pecci T, Tassan G, Verrusio W, Marigliano V, Cacciafesta M (2009) Exaggerated morning blood pressure surge and cardiovascular events. A 5-year longitudinal study in normotensive and well-controlled hypertensive elderly. Arch Gerontol Geriatr 49, e105-e109.

[64] Melendez JC, Satorres E, Redondo R, Escudero J, Pitarque A (2018) Wellbeing, resilience, and coping: Are there differences between healthy older adults, adults with mild cognitive impairment, and adults with Alzheimer-type dementia? Arch Gerontol Geriatr 77, 38-43.

[65] Petermann-Rocha F, Lyall DM, Gray SR, Esteban-Cornejo I, Quinn TJ, Ho FK, Pell JP, Celis-Morales C (2020) Associations between physical frailty and dementia incidence: A prospective study from UK Biobank. Lancet Healthy Longev 1, e58-e68.
[66] Dolan E, O'Brien E (2015) Is it daily, monthly, or yearly blood pressure variability that enhances cardiovascular risk? Curr Cardiol Rep 17, 93.

[67] Parati G, Ochoa JE, Lombardi C, Bilo G (2015) Blood pressure variability: Assessment, predictive value, and potential as a therapeutic target. Curr Hypertens Rep 17, 537.

[68] Gosmanova EO, Mikkelsen MK, Molnar MZ, Lu JL, Yessayan LT, Kalantar-Zadeh K, Kovesdy CP (2016) Association of systolic blood pressure variability with mortality, coronary heart disease, stroke, and renal disease. J Am Coll Cardiol 68, 1375-1386.

[69] Olde Rikkert MGM, Melis RJF (2019) Rerouting geriatric medicine by complementing static frailty measures with dynamic resilience indicators of recovery potential. Front Physiol 10, 723.

[70] Webb AJ, Fischer U, Mehta Z, Rothwell PM (2010) Effects of antihypertensive-drug class on interindividual variation in blood pressure and risk of stroke: A systematic review and meta-analysis. Lancet 375, 906-915.

[71] Law MR, Morris JK, Wald NJ (2009) Use of blood pressure lowering drugs in the prevention of cardiovascular disease: Meta-analysis of 147 randomised trials in the context of expectations from prospective epidemiological studies. BMJ 338, b1665.

[72] Lindholm LH, Carlberg B, Samuelsson O (2005) Should beta blockers remain first choice in the treatment of primary hypertension? A meta-analysis. Lancet 366, 1545-1553.

[73] Rothwell PM, Howard SC, Dolan E, O'Brien E, Dobson JE, Dahlof B, Poulter NR, Sever PS, Ascot B, Investigators MRCT (2010) Effects of beta blockers and calcium-channel blockers on within-individual variability in blood pressure and risk of stroke. Lancet Neurol 9, 469-480. 